\title{
Exploring barriers and facilitators to the clinical use of virtual reality for post-stroke unilateral spatial neglect assessment
}

\section{Tatiana Ogourtsova, Philippe S. Archambault \& Anouk Lamontagne}

To cite this article: Tatiana Ogourtsova, Philippe S. Archambault \& Anouk Lamontagne (2019) Exploring barriers and facilitators to the clinical use of virtual reality for post-stroke unilateral spatial neglect assessment, Disability and Rehabilitation, 41:3, 284-292, DOI: 10.1080/09638288.2017.1387292

To link to this article: https://doi.org/10.1080/09638288.2017.1387292

Published online: 07 Nov 2017.

Submit your article to this journal $\sqsubset$

Lll Article views: 786

Q View related articles $₫$

View Crossmark data

Citing articles: 3 View citing articles $[7$ 


\title{
Exploring barriers and facilitators to the clinical use of virtual reality for post-stroke unilateral spatial neglect assessment
}

\author{
Tatiana Ogourtsova ${ }^{a, b}$, Philippe S. Archambault ${ }^{a, b}$ (D) and Anouk Lamontagne $e^{a, b}$ \\ ${ }^{\mathrm{a} S}$ School of Physical and Occupational Therapy, McGill University, Montreal, QC, Canada; ${ }^{\mathrm{b}}$ Feil-Oberfeld Research Centre, Jewish Rehabilitation \\ Hospital, Laval, QC, Canada
}

\begin{abstract}
Background: Hemineglect, defined as a failure to attend to the contralesional side of space, is a prevalent and disabling post-stroke deficit. Conventional hemineglect assessments lack sensitivity as they contain mainly non-functional tasks performed in near-extrapersonal space, using static, two-dimensional methods. This is of concern given that hemineglect is a strong predictor for functional deterioration, limited post-stroke recovery, and difficulty in community reintegration. With the emerging field of virtual reality, several virtual tools have been proposed and have reported better sensitivity in neglect-related deficits detection than conventional methods. However, these and future virtual reality-based tools are yet to be implemented in clinical practice.

Objectives: The present study aimed to explore the barriers/facilitators perceived by clinicians in the use of virtual reality for hemineglect assessment; and to identify features of an optimal virtual assessment.

Methods: A qualitative descriptive process, in the form of focus groups, self-administered questionnaire and individual interviews was used.

Results: Two focus groups ( $n=11$ clinicians) were conducted and experts in the field $(n=3)$ were individually interviewed. Several barriers and facilitators, including personal, institutional, client suitability, and equipment factors, were identified. Clinicians and experts in the field reported numerous features for the virtual tool optimization.

Conclusion: Factors identified through this study lay the foundation for the development of a knowledge translation initiative towards an implementation of a virtual assessment for hemineglect. Addressing the identified barriers/facilitators during implementation and incorporating the optimal features in the design of the virtual assessment could assist and promote its eventual adoption in clinical settings.
\end{abstract}

\section{ARTICLE HISTORY}

Received 13 March 2017

Revised 10 August 2017

Accepted 28 September 2017

\section{KEYWORDS}

Knowledge translation qualitative research; hemineglect; evaluation; technology; cerebrovascular accident

\section{> IMPLICATIONS FOR REHABILITATION}

- A multimodal and active knowledge translation intervention built on the presently identified modifiable factors is suggested to be implemented to support the clinical integration of a virtual realitybased assessment for post-stroke hemineglect.

- To amplify application and usefulness of a virtual-reality based tool in the assessment of post-stroke hemineglect, optimal features identified in the present study should be incorporated in the design of such technology.

\section{Background}

Stroke is the leading cause of adulthood disability as it frequently results in residual motor, sensory, perceptual and/or cognitive impairments [1]. Unilateral spatial neglect (USN) is a common sequela of stroke characterized by the inability to orient, respond, or report to the stimuli present on the contralesional side [2]. It is known to seriously affect patient-related outcomes such as functional independence, community reintegration, and quality of life $[3,4]$. Given that the global annual incidence of stroke is nearly 15 million [5], and that up to $48 \%$ of those with a right hemisphere stroke will experience USN and its devastating effects [6], the use of sensitive USN detection and effective therapy is crucial.

Despite these alarming numbers, research has shown that clinicians do not consistently use the available standardized USN assessments. For instance, surveys indicate that only $13-27 \%$ of clinicians in acute and subacute care facilities respectively use a standardized USN assessment tool, and that only the near-extrapersonal space USN is evaluated [7,8]. Inefficient USN detection, or lack thereof, is a significant issue, given that USN is associated with greater risk for falls, functional deterioration, difficulty performing activities of daily living, and instrumental activities of daily living $[2-4,6]$; therefore, posing an important hazard when discharging these individuals home and to community-living activities such as driving, going to back to work, caring for family, and community ambulation.

Unfortunately, sensitive detection using the currently available conventional methods is limited given that these tools do not grasp all the facets of USN's multimodal and heterogeneous presentation. In fact, despite an extensive body of research on USN standardized assessment tools, there is currently no gold-standard. The commonly employed paper-and-pencil evaluations can result in misdiagnosis of subjects with mild USN [6]. To exemplify, the 
large range of USN incidence that is commonly reported in the literature (i.e., 13-81\% [9]) is suggested to be a result of the different evaluation methods used and of the paper-and-pencil tools' low sensitivity and ecological validity [9]. This lack of sensitivity is demonstrated by studies that reported participants with recovered USN based on conventional paper-and-pencil tests showing residual deficits when more complex, challenging and/or functional tasks are employed. For example, Berard et al. [10] reported that patients who were classified as recovered, based on paperand-pencil USN tests, were found to have altered walking trajectory adjustments in response to changes in visual motion stimuli presentation in far space. Other studies found that paper-and-pencil USN tests failed to predict functional performance in various mobility tasks such as wheelchair navigation [11,12] and in an obstacle avoidance task performed while walking [13]. Likewise, patients who demonstrated absence of USN on conventional tests exhibited clear perceptual deficits in a virtual reality (VR) threedimensional detection time task [14]. Such findings lead to speculate that the conventional paper-and-pencil tests are limited in their ability to pick up milder USN cases, predict functional performance in daily life, and are highly bounded by assessing USN within the near-extrapersonal space only, using static, two-dimensional methods. With the rapidly growing field and industry of virtual reality (VR), these USN diagnostic techniques could be enhanced and augmented to include three-dimensional images or stereovision, far space targets, and functional everyday tasks.

VR is a computer-based, multisensory, stimulating, and interactive environment that occurs in real time; where the individual is engaged in activities that appear similar to real-world objects and/or events [15-17] and has a strong "sense of presence" [18]. In the last decade, different VR-based USN assessments have been proposed (reviewed in Ref. [19]), and some were found to be more sensitive in detecting the presence of deficits in cases where conventional USN assessment was negative [11,12,14,20-24]. However, the application of these tools in clinical settings remains limited. Despite their promising results over conventional methods, the acceptance and future use of these technologies in clinical practice depends on barriers and facilitators perceived by the end-users (i.e., clinicians). When facilitators are minimized and barriers are not addressed, the acceptance of technology declines and end-users renounce its clinical application [25]. In addition, as per Graham et al. [26], the barriers and facilitators need to be identified and subsequently included in the ensuing knowledge translation (KT) intervention geared towards increasing the use of evidence-based practice. For instance, a multifaceted KT intervention, recently designed by Levac et al. [27], was shown to increase clinicians' self-efficacy, perceived behavioral control, and facilitating conditions in the use of VR for post-stroke rehabilitation: the GestureTek Interactive Rehabilitation Exercise (IREX, GestureTek, Toronto, ON, Canada) software platform providing interactive games that address various upper extremity and full body movement goals. Similarly, other studies examining clinical barriers/ facilitators outside of research context focused on VR for physical impairments post-brain injury in adults [28] and children [29], post-traumatic stress disorder among returning veterans [30], and for burn-related pain control [31]. To the best of our knowledge, however, no studies have evaluated support needs and modifiable barriers that could influence the application and use of VR specifically for post-stroke USN management. In relation to this, having already conducted a systematic literature review and developed a VR-based USN assessment and treatment toolkit [19], as well as preliminary testing of a novel VR-based USN functional assessment tool evidencing its superior detection sensitivity in comparison to conventional methods [32], there is a need to refine our understanding of the barriers and facilitators to the use of VR for USN management. Further, to promote its application and usage adherence in clinical practice, we seek to tailor VR-based USN assessment to clinicians' needs, while also considering the opinions of experts as to the tool's optimal features.

Thus, the objectives of this study were to: (1) identify the facilitators and barriers that affect the use of VR for post-stroke USN assessment by clinicians; and (2) identify the features of an optimal VR-based USN assessment that could be implemented and used by clinicians in the management of post-stroke USN.

\section{Methods}

\section{Study design}

A qualitative descriptive approach, in the form of a [AQ1] triangulation research strategy, was employed in the present study (i.e., use of multiple methods or data sources to develop a comprehensive understanding of a phenomena [33]). More precisely, a focus group methodology and a self-administered paper-based questionnaire were used to explore clinicians' perceptions of the barriers and facilitators to the use of VR for post-stroke USN assessment. In addition, clinicians were asked to identify what would be the features of an optimal VR-based USN assessment tool. This latter information was then complemented with individual interviews with experts in the field. A focus group approach was selected with the clinicians given that it can promote the creation and sharing of ideas amongst participants, possibly leading to insights beyond those obtained through individual interviews $[34,35]$. Experts in the field were individually interviewed to accommodate for their different geographical locations around the world and their schedule constraints. The study was approved by the Centre de Recherche Interdisciplinaire en Réadaptation (CRIR, Quebec, Canada) Institutional Review Board and all participants provided their informed consent.

\section{Participants}

Purposive sampling was used to identify key informants with insights into the subject of interest [36] and to ensure a broad representation of topics. Given that Occupational Therapists are involved in the assessment and treatment of signs and symptoms of post-stroke USN [7,8], participants were selected from the pool of Occupational Therapists working with stroke patients in two rehabilitation centers providing in- and out-patient rehabilitation services in the Greater Montreal area (Quebec, Canada). Occupational Therapists were eligible if they were registered with the provincial licensing body, had at least 3 months of experience working with a stroke clientele in a rehabilitation setting, currently treated a minimum of two adults with stroke per month, and were fluent in English and/or in French. Therapists could participate in the study regardless of their gender, age, and experience with the use of VR. Experts in the field were also recruited based on purposive sampling and were eligible if they held a graduate degree (i.e., MSc or PhD) and conducted research and/or educational activities pertaining to at least one of the following subjects: VR, stroke rehabilitation, post-stroke USN.

\section{Sample size consideration}

In the qualitative research literature, the number of focus groups and sample size within focus groups vary significantly [37]. Several guidelines, however, recommend to include a minimum of four and a maximum of 12 participants per group to optimize 
individual participation and generate rich discussions [38-40]. It was also reported that conducting two focus groups with fewer participants instead of one focus group with more participants would limit the bias that might be seen in a single group or site and allow to examine more themes across groups [41]. It was thus decided to recruit 4-12 clinicians per focus group and to conduct a minimum of two focus groups until saturation of ideas was reached (i.e., until no new themes emerged). Transcripts and selfadministered questionnaire responses from the first focus group were thus reviewed to reflect on that session before conducting the second focus group, thereby enabling initially identified concepts to be examined in the second session and promote data saturation. Data saturation was further ensured by using a second coder for thematic analysis and the usage of diverse methods (focus groups, individual interviews, and self-administered questionnaires) [42]. In addition, all discussion points were noted on the screen viewed by participants and focus groups were ended with the moderator providing a summary of the discussed points. Participants were asked then if the summary is reflective of what was discussed and if they can think of other elements. The focus group was terminated when no new ideas emerged following the summary/closing remarks statement.

\section{Data collection}

\section{Focus groups}

According to guidelines on the organization of focus groups [38], a plan was developed to assist with the running of the groups. To begin, a 15-min presentation on general information about poststroke USN and VR was provided. Following this, four open-ended discussion questions were conversed among the participants for 45-60 min. Those questions were pre-determined, reviewed, and agreed upon by the authors of the manuscript: "(1) How do you feel about using virtual reality in your practice to evaluate and/or treat post-stroke USN?; (2) What do you like best about the idea of using virtual reality to evaluate and/or treat post-stroke USN?; (3) What are your concerns with using a virtual reality tool for post-stroke USN assessment and treatment?; (4) According to you, what would an optimal virtual reality assessment tool for poststroke USN look like/include/be comprised of?". Finally, participants completed a self-administered questionnaire that took 5-10 min. All questionnaires were completed privately, anonymously, without peer/investigator influence. The entire process lasted 1-1.5 h. A moderator (T.O.) and one assistant (external to the study and whose role was to note discussion points on slides visible to the group participants) were present at all times. The groups were conducted in French and/or in English as per participants' preference. Participants received no monetary reward for their participation; however, a catered lunch was offered during the initial informative presentation.

\section{Questionnaire}

The self-administered paper-based questionnaire (7-point Likert scale, ranging from "strongly disagree" to "strongly agree") on institutional and personal barriers was developed with guidance from the Unified Theory of Acceptance and Use of Technology (UTAUT) Model [43]. The UTAUT model proposes that four out of seven constructs are significant, direct determinations of behavioral intention to use the system and include: (1) Performance Expectancy: the degree to which the individuals believe that the use of the technologies will results in performance gains; (2) Effort Expectancy: the ease of use of the technologies; (3) Social Factors/ Influence: the extent to which the individuals believe that important others believe that they should use the technologies; and (4) Facilitating Conditions: the perceived extent to which the organizational and technical infrastructure exists to support use of the system. On the other hand, the remaining three constructs of (5) Self-efficacy; (6) Attitudes towards Technology; and (7) Anxiety towards Technology Use were shown to neither be direct determinants nor have a significant role in affecting behavioral intention to use the system. As a result, we chose to exclude these last three constructs from our questionnaire.

The reliability and validity of questionnaires using UTAUT model have been previously explored [44,45]. The questionnaire in this study was reviewed for face validity by all authors of the manuscript, initially developed in English and then translated from English to French. Translation was verified for its accuracy by four individuals (two authors of this article (T.O. and A.L.) and two individuals which were not part of the study development or participation). The questionnaire also included a section (Part I) on the information about clinicians' demographic factors and professional characteristics including age, gender, time spent on continuing education, degree, work schedule, experience with stroke clientele, specialty certification, teaching activities, and work environment.

\section{Individual interviews}

The individual interviews with experts in the field were conducted following the focus group analysis. Interviews were conducted via Skype $^{\circledR}$ or telephone and the audio of the conversation was recorded. Participants were given an overview of post-stroke USN and VR, as well as preliminary results of the focus group analysis. They were then asked to discuss what would an optimal VR-based post-stroke USN assessment tool include. The interviews lasted 20-60 min and were all conducted in English.

\section{Data analysis}

Descriptive statistics were used to summarize demographic data of the focus group participants and experts in the field. For the questionnaire, data was summarized by frequency counts in each question/category. The focus groups were videotaped and the audio data were transcribed. The verbatim transcription was then imported into the NVivo software (QSR International, Australia) for data management. The French statements from both groups were translated into English following the verbatim transcription using a back-translation method. Triangulation methods were used for analysis of the data [46]. More specifically, the first author (T.O.) read the entire transcript to gain a general sense of the content's meaning. The transcript's content was then analyzed by generating initial codes for all meaningful ideas emerging from the data, using a directed content-based analysis technique [47]. Following this and a second coder (M.B. - a clinician with research experience who was not a study participant nor assisted with the focus groups in any way) coded the entire transcript using the coding grid. Codes that emerged from the data during the second coding procedure that could not be categorized using the existing grid were further discussed among both raters to explore their meaning and/or relationship to other codes, and a consensus was reached. A final round of analysis was then performed by the first author (T.O.) to ensure that all relevant statements were coded and that agreement between raters was at $100 \%$. The recorded interviews with experts in the field were analyzed separately from the focus groups. The interviews were transcribed verbatim and emergent themes, optimal features of a VR-based USN assessment, were selected from the discussion by the first author (T.O.). 


\section{Results}

\section{Descriptive variables}

The two focus groups included $11(n=11)$ occupational therapists: four $(n=4)$ in the group held in French (Group 1 at clinical site 1) and seven $(n=7)$ in the group held in English/French (Group 2 at clinical site 2). Table 1 presents the clinician's personal and professional characteristics. Participants were aged $31.3 \pm 4.5$ years old, with a Bachelor or Professional Master's degree obtained anytime from 1995 to 2013. Most of the participants were full time clinicians with 1 to more than 10 years of experience with stroke patients. Eight participants spend $2 \mathrm{~h}$ or less per month on selfeducational activities (e.g., reading articles, conferences, searching evidence-based engines, etc.) and only two had previous experience with VR.

Seven $(n=7)$ experts in the field were originally contacted for interview. Two $(n=2)$ declined to participate and no response was obtained from two $(n=2)$ other candidates; therefore, three $(n=3)$ individuals were included in the study and interviewed (Table 2). All experts in the field had previous exposure (active research, presentations, and conferences) to USN, and two of the three had previous active research experience with VR.

\section{Barriers and facilitators}

Self-administered questionnaire

All clinician participants completed the self-administered questionnaire without any missing data. Table 3 shows the overall perception of therapists about VR for the use of post-stroke USN assessment according to UTAUT constructs. The questionnaire responses demonstrate that: (1) clinicians agreed that their work goals and patients' outcomes can be augmented through the use of VR for post-stroke USN assessment (Performance Expectancy); (2) clinicians slightly agreed that VR for post-stroke USN could be easy to use or not complicated to use (Effort Expectancy); (3) clinicians tended to be neutral with their perception that the intention to use the VR assessment for post-stroke USN is positively influenced by the opinions and perceptions of other therapists in their workplace (Social Influence); (4) clinicians disagreed that they have the available resources and knowledge necessary to use such a tool; and almost all reported the need for a resource person to assist in its use (Facilitating Conditions); and finally (5) clinicians showed a strong trend in behavioral intentions to use VR for post-stroke USN assessment (Behavioral Intention to Use the System).

Overall, the following facilitators emerged from the answered questionnaire: personal (performance and effort expectancy, positive attitude, no fear/anxiety towards VR, and intention of use), institutional organization (support, resource person, and built-in help facility). On the other hand, the questionnaire unfolded the following barriers: personal (lack of knowledge) and institutional organization (necessary resources).

\section{Focus groups}

Thematic analysis of the clinicians' comments on facilitators and barriers to the use of VR for post-stroke USN assessment revealed several natural groupings under barriers $(n=5)$ and facilitators $(n=7)$. The key themes voiced by the group were abstracted and are described below, as are salient comments ascribed to the various themes.

Table 1. Personal and professional characteristics of focus groups' participants.

\begin{tabular}{|c|c|c|}
\hline Variable & Group $1(n=4 ; \mathrm{P} 1 \mathrm{a}-4 \mathrm{a})$ & Group 2 ( $n=7$ P1b-7b) \\
\hline Age at evaluation (mean \pm SD) & $29.1 \pm 3.8$ & $33.4 \pm 5.2$ \\
\hline Gender ratio (M:F) & $0: 4$ & $0: 7$ \\
\hline Degree and year of graduation (range) & BSc or MSc (Applied)/2008-2012 & BSc or MSc (Applied)/1995-2013 \\
\hline Work schedule & Full time ${ }^{a}(n=4)$ & $\begin{array}{l}\text { Full time }{ }^{\mathrm{a}}(n=6) \\
\text { Part time }^{\mathrm{b}}(n=1)\end{array}$ \\
\hline Experience with stroke rehabilitation (years) & $4-10$ & 1 to $>10$ \\
\hline Number of patients per day (range) & $2-5(n=4)$ & $\begin{array}{l}6-10(n=4) \\
2-5(n=3)\end{array}$ \\
\hline Evaluation versus treatment time per day (h, range) & 1-2: 4-6 & $0.75-3: 3-7$ \\
\hline Continuing education in stroke rehabilitation (h/month) & $\leq 2(n=4)$ & $\begin{array}{l}\leq 2(n=4) \\
2-5(n=3)\end{array}$ \\
\hline Clinicians with University teaching experience $(n)$ & 1 & 4 \\
\hline Clinicians having experience with VR $(n)$ & 0 & $2^{c}$ \\
\hline
\end{tabular}

Standard deviation (SD); Male (M); Female (F); Bachelor in Science (BSc); Masters in Science (MSc); number (n); Virtual reality (VR); Participant (P).

${ }^{\mathrm{a}}$ Full time $=\geq 35 \mathrm{~h} /$ week.

${ }^{\mathrm{b}}$ Part time $=<35 \mathrm{~h} /$ week.

'Presentations, conferences, and research.

Table 2. Characteristics of experts in the field.

\begin{tabular}{|c|c|c|c|}
\hline Variable & Participant 1 & Participant 2 & Participant 3 \\
\hline Gender & M & $\mathrm{F}$ & $M$ \\
\hline Degree of graduation and year & PhD (2004) & MSc Thesis (2012) & $\begin{array}{c}\text { MD (1986) - Specialist in Physical } \\
\text { Medicine, Rehabilitation \& } \\
\text { Neuropsychiatry }\end{array}$ \\
\hline Expertise areas & $\begin{array}{l}\text { Brain Injury; Movement Control; } \\
\text { Neuropsychology; Neuroscience; } \\
\text { Rehabilitation/Therapy; Stroke; Virtual } \\
\text { Reality }\end{array}$ & $\begin{array}{c}\text { USN; Stroke Rehabilitation; Knowledge } \\
\text { Translation; Traumatic Brain Injury; } \\
\text { Cognition }\end{array}$ & $\begin{array}{c}\text { Stroke rehabilitation; Neurorehabilitation; } \\
\text { Motion Analysis; Motor Cognition and } \\
\text { Learning; Perception; Neurodegenerative } \\
\text { Disorders }\end{array}$ \\
\hline University teaching experience & Yes & Yes & Yes \\
\hline VR experience & $Y_{e s}^{a}$ & $Y_{e s}^{b}$ & $Y_{e s}^{a}$ \\
\hline USN experience & $Y_{e s}{ }^{a b}$ & $Y_{e s}{ }^{a b}$ & $Y_{e s}{ }^{a b}$ \\
\hline
\end{tabular}

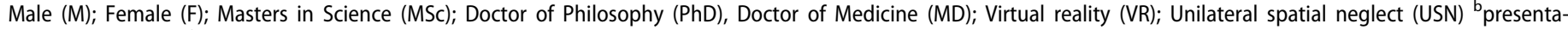
tions, conferences, a active research area. 
Table 3. Response frequencies by unified theory of acceptance and use of technology model constructs.

\begin{tabular}{|c|c|c|c|c|c|c|c|}
\hline & $\begin{array}{l}\text { Strongly } \\
\text { disagree }\end{array}$ & $\begin{array}{c}\text { Quite } \\
\text { disagree }\end{array}$ & $\begin{array}{l}\text { Slightly } \\
\text { disagree }\end{array}$ & $\begin{array}{l}\text { Neither agree } \\
\text { nor disagree }\end{array}$ & $\begin{array}{l}\text { Slightly } \\
\text { agree }\end{array}$ & $\begin{array}{l}\text { Quite } \\
\text { agree }\end{array}$ & $\begin{array}{c}\text { Strongly } \\
\text { agree }\end{array}$ \\
\hline \multicolumn{8}{|l|}{ Performance expectancy } \\
\hline $\begin{array}{l}\text { I will find virtual reality (VR) for post-stroke unilateral spatial neg- } \\
\text { lect (USN) assessment useful in my job }\end{array}$ & 1 & & & & 3 & 4 & 3 \\
\hline $\begin{array}{l}\text { Using VR for post-stroke USN assessment will enable me to accom- } \\
\text { plish tasks more quickly }\end{array}$ & & & & 2 & 3 & 6 & \\
\hline $\begin{array}{l}\text { Using VR for post-stroke USN assessment will increase my } \\
\text { productivity }\end{array}$ & & & 1 & 3 & 5 & 2 & \\
\hline \multicolumn{8}{|l|}{ Effort expectancy } \\
\hline $\begin{array}{l}\text { My interaction with VR for post-stroke USN assessment would be } \\
\text { clear and understandable }\end{array}$ & & & & 1 & 6 & 3 & 1 \\
\hline $\begin{array}{l}\text { It would be easy for me to become skillful at using VR for post- } \\
\text { stroke USN assessment }\end{array}$ & & & & & 4 & 5 & 2 \\
\hline \multicolumn{8}{|l|}{ Social influence } \\
\hline $\begin{array}{l}\text { People who influence my behavior at work think that I should use } \\
\text { VR for post-stroke USN assessment }\end{array}$ & & 1 & & 9 & 1 & & \\
\hline $\begin{array}{l}\text { People who are important to me think that I should use VR for } \\
\text { post-stroke USN assessment }\end{array}$ & & 1 & & 10 & & & \\
\hline $\begin{array}{l}\text { The senior management of this institution would be helpful in the } \\
\text { use of VR for post-stroke USN assessment }\end{array}$ & 1 & 1 & & 7 & 2 & & \\
\hline $\begin{array}{l}\text { In general, I feel that the organization will support me in the use } \\
\text { of VR for post-stroke USN assessment }\end{array}$ & & & 1 & 1 & 5 & 4 & \\
\hline \multicolumn{8}{|l|}{ Facilitating conditions } \\
\hline $\begin{array}{l}\text { I have resources necessary to use VR for post-stroke USN } \\
\text { assessment }\end{array}$ & 1 & 4 & 3 & 2 & 1 & & \\
\hline $\begin{array}{l}\text { I have the necessary knowledge to use VR for post-stroke USN } \\
\text { assessment }\end{array}$ & 2 & 3 & 3 & 1 & 2 & & \\
\hline $\begin{array}{l}\text { I would like a specific person (or group) would be available for } \\
\text { assistance with VR for post-stroke USN assessment difficulties }\end{array}$ & & & & & & 1 & 10 \\
\hline $\begin{array}{l}\text { I think I could complete a job or a task using VR for post-stroke } \\
\text { USN assessment if there was no one around to tell me what to } \\
\text { do as I go }\end{array}$ & 3 & 2 & 2 & 1 & 3 & & \\
\hline $\begin{array}{l}\text { I think I could complete a job or a task using VR for post-stroke } \\
\text { USN assessment if I could call someone for help if I get stuck }\end{array}$ & & & & & 1 & 6 & 4 \\
\hline $\begin{array}{l}\text { I think I could complete a job or a task using VR for post-stroke } \\
\text { USN assessment if I had a lot of time to complete the job for } \\
\text { which the software was provided }\end{array}$ & 1 & 1 & 1 & 4 & 1 & 2 & 1 \\
\hline $\begin{array}{l}\text { I think I could complete a job or a task using VR for post-stroke } \\
\text { USN assessment if I had just the build-in help facility for } \\
\text { assistance }\end{array}$ & 2 & 1 & 3 & & 3 & 1 & 1 \\
\hline \multicolumn{8}{|l|}{ Behavioral intention to use the system } \\
\hline $\begin{array}{l}\text { If made available to me, I intend to use VR for post-stroke USN } \\
\text { assessment in the next } 12 \text { months }\end{array}$ & & & & & & 7 & 4 \\
\hline $\begin{array}{l}\text { If made available to me, I predict I would use VR for post-stroke } \\
\text { USN assessment in the next } 12 \text { months }\end{array}$ & & & & & 2 & 6 & 3 \\
\hline $\begin{array}{l}\text { If made available to me, I plan to use VR for post-stroke USN } \\
\text { assessment in the next } 12 \text { months }\end{array}$ & & & & & 2 & 6 & 3 \\
\hline
\end{tabular}

The highlighted boxes indicate to the response category chosen by most of the focus group participants; Virtual reality (VR); Unilateral spatial neglect (USN).

\section{Barriers - client suitability}

Four different themes emerged around client suitability as a barrier: old age, infection control, functional level, and deficits that may impact participation in VR:

P1a: The older clients, they are afraid of computers, they have a lot of anxiety: "I never used that, I would not use that" (quoting a client). This [anxiety] could affect their results. We won't of course use it [VR] only in evaluation. But, it is one of the preoccupations that older persons can express.

P4b: For patients with MRSA [Methicillin-resistant Staphylococcus aureus], can we use it [VR]?

\section{Barriers - equipment}

Several topics emerged around the barriers related to equipment: availability, cost, lack of generalization, side effects, and space/ training requirements:

P3b: There is also an aspect of generalization. Are the results of it [VR] are transferrable to real-life functioning?
P2a: Maybe I am afraid to have aftereffects following its [VR] use. I have apprehensions towards this. I don't want my patient to be nauseous or to vomit after the therapy session. It is this kind of things on a practical level that makes me say that I don't really want to use that [VR].

P4b: [I have preoccupations towards] the time to get to know it [VR], for us - the clinicians.

\section{Barriers - personal}

Personal barriers included anxiety, lack of VR experience and resources, lack of knowledge about VR and/or USN, unwillingness to use VR or other standardized measure, and time:

P1a: I have hard time to understand how it [VR] can be used as an assessment, given that we already have a very functional and ecological environment to evaluate our patients, we have the grocery store. So I don't think that I would tend to use it [VR] for evaluation.

P2a: It is certainly what we will do with this information knowing that he [patient] has no difficulties in daily activities, if we do not see it in daily activities. Therefore, at this moment, I do not know what I will do 
with this information [coming from VR assessment]. We have short hospital stays, so when the patient is independent in self-care activities, we send him [patient] home.

P2a: I understand that it [VR] could be more sensible than the line bisection test, but it cannot measure USN in the personal space. When a patient is shaving on one side, it is not with VR that I will assess or treat that. Even on extrapersonal level, I do not know at which point VR is really for extrapersonal space. It could be more fun since we have less tools, but it remains that it [USN of extrapersonal space] is very specific $\{\ldots\}$ so there are not that many patients per year. If I have one patient per year with this [USN of extrapersonal space], even that -1 find is a lot.

\section{Facilitators - client suitability}

The point that VR might be suitable for the younger individuals with stroke given their drive for technology and previous exposure to technology came out on several occasions:

P5b: It [VR] would be good for our young clients. They are already attracted to technology.

\section{Facilitators - equipment}

Facilitators related to equipment such as precision, sensitivity, variability, accessibility, generalizability, training, versatility, and builtin help were reported:

P5b: It [VR] can give us more tools, and tools that would allow us to evaluate things outside of the near space, without necessarily going in the real environment.

P3b: To have access to higher level activities because it [VR] is very multimodal. It [VR] is more visual, the client moves, there is more stimuli so it makes it more interesting. It [VR] could allow to detect more problems than we would see with our conventional evaluation tools.

\section{Facilitator - institutional organization}

Institutional organization facilitators such as resource person/ assistance were discussed for overall management including assessment and treatment using VR:

P7b: I will use it [VR] as long as there is a resource or assistant person.

In fact, if there is a resource/assistant person, he [assistant] can write a journal reflecting the activities of the person - what they did in treatment, how he [patient] performed. In this way, us as therapists, we can see the feedback and the evolution of the patient.

\section{Facilitator - personal}

Several facilitators on the personal level emerged and included: knowledge of important of USN assessment using sensitive methods, willingness or interest towards VR use for USN (intention of use), positive attitudes towards VR, time, performance, and effort expectancy:

P1b: For my part, for USN evaluation, we [clinicians] are in lack of assessment for USN since a long time. I remember we had students that came in early 2000's presenting that the BIT [Behavioral Inattention Test] was the best that we have at the moment. We use it very rarely, given that we see that the patient has USN; however, patients tend to do well on those tests [BIT subtests], and it [BIT] doesn't necessarily measure the change.

Especially, for the out-patients, there are patients that I follow until the driving assessment stage, and I do not have tools that inform me of their improvements or lack of thereof of the USN. So for the tasks that are paper and pencil, it [their performance] is not bad, but we see them [patients] from time to time neglecting obstacles in their space, bumping into left-sided obstacles. So, it would be very interesting to have sensible tools.
P6b: I like that it [VR for USN assessment] can be repeated in time, for example in in-patient, then in out-patient, to see the evolution/ progression, rather than just evidencing it [USN of extrapersonal space] by walking for example. We are currently very limited in conventional extrapersonal-space USN assessment.

\section{Optimal features of VR-based USN assessment}

Optimal features of a VR-based post-stroke USN assessment were identified. Clinicians reported that they would be open to use an immersive, three-dimensional tool that has a simple/intuitive start up system, with individual files saving options and that can print out reports of performance/progress. They conveyed that performed tasks should be client-centered and functional, including activities centered around leisure, instrumental and self-care activities of daily life, near and far-extrapersonal USN assessment, and having an option of different tasks to perform as per the patient's preference. Clinicians would like to complete the VR USN assessment in 30-60 min and they expressed an interest in receiving training on the device and running of the system.

Experts reported the following additional features: presence of attentional distractors, ability to adjust the attentional load of the task, eye tracking during tasks, gaze and movement coordination tasks (e.g., transfer from near- to far-extrapersonal space through navigation), goal-directed space navigation (e.g., following the principles of the zoo map subtest of the Behavioral Assessment of Dysexecutive Syndrome [48]) and locomotor tasks within limited space (e.g., using treadmill or stationary robotics that can change directions), a VR version of conventional tests (e.g., VR-based line bisection and cancelation tasks in near and far space), targets placed in space using polar coordinates, and symmetrically designed environments. The common features to those reported by clinicians included functional tasks in 3D immersive environments with an adjustable level of difficulty, near and far space tasks, simple start up and analysis of results, and clear guidelines and training. The latter two factors were expressed not only as optimal features of a tool by experts in the field, but also as facilitators (equipment/personal) for its implementation and adherence to its use.

\section{Discussion}

To the best of our knowledge, this study is the first to highlight the barriers and facilitators to the clinical use of a VR-based assessment tool for post-stroke USN. The key barriers that were identified, including personal, institutional, equipment, and client suitability, will help optimize the design and implementation of future VR-based USN tools in clinical practice. A multimodal and active KT intervention can now be designed [27] according to the identified support needs and modifiable barriers. For instance, addressing factors of lack of knowledge about VR use and importance of USN-sensitive assessments as well as lack of resources in the clinical setting could influence VR adoption and its sustainable use for USN management. The personal barrier of lack of knowledge about USN and the importance of USN-sensitive assessment (e.g., please refer to comment of $P 2 a$ under that category) is highly concerning, demonstrating that a clinician, working fulltime on a stroke rehabilitation ward, does not see the need for a sensitive post-stroke USN assessment of peripersonal space (nearand far-extrapersonal space) that in fact is known to be greatly prevalent among those with right hemisphere stroke and often left undetected using conventional methods or observation. Based on this study, we propose the following interventions and elements geared towards increasing the knowledge-base of scholarly 
practitioners about post-stroke USN, its assessment, and the VR technology: the addition of a specialized course in visual-perception and related-technologies in the current OT educational curriculum, multifaceted KT interventions for clinicians including hands-on workshop experiences, e-learning modules, case studies, experts' panel discussions, a designated expert clinician (champion or mentor) or resource person in each targeted setting, training and ongoing support in the use of chosen technologies, and evaluation of change in practice following the KT interventions.

The finding that most of the participating clinicians were open to the use of VR and had a positive attitude towards its use for post-stroke USN indicates that there is a potential in continuing to pursue the knowledge to action model cycle with the aim of improving current practices as described by Graham et al. [26] Specifically, present results could be employed to plan for a future implementation of a VR-based USN assessment tool in a clinical setting, monitor its use and evaluate what changes it brings to the clinical post-stroke USN management. To tackle most of the representative population (individuals with post-stroke UNS), we propose that the implementation of a VR-based USN assessment tool should initially occur in rehabilitation centers providing stroke rehabilitation services, and be integrated with other occupational therapy evaluation procedures. This would complement existing findings and provide data on concurrent validity and sensitivity with respect to the conventional methods employed in that setting. Thereafter, a broader implementation could be foreseen to private, community, and acute-care settings.

The results of the self-administered questionnaire in our study are consistent with previously published reports on behavioral intention to use technologies in healthcare settings. For instance, our results, showing an agreement among clinicians that a VRbased USN assessment can enhance their performance and ensuring patients' outcomes (i.e., performance expectancy) are in accordance with a larger cross-sectional exploratory study by Liu et al. [45]. Using the UTAUT-based questionnaire, they found that performance expectancy was the most significant factor in determining Occupational and Physical therapists' acceptance and use of technology in rehabilitation [45]. Similarly to the responses of clinicians' in the present study, effort expectancy [45,49-51] and social influence [45] were not found to be salient factors influencing behavioral intention to use technologies in studies using the UTAUT-based questionnaires with different health professionals including medical doctors, health educators, nurses, as well as Occupational and Physical Therapists. Promisingly, participants in the present study, similar to those in Liu et al. study, expressed their intention to use the newly available technology, confirming previously found clinicians' positive attitudes towards VR.

The findings of the present study offer multiple practical implications. First, the identified factors that influence clinicians' acceptance and adoption of VR for post-stroke USN assessment can inform future research on priorities for the planning of training programs and of the resources needed for the effective acquisition and implementation of such technology. The interviewees in the present study were critical regarding barriers related to VR equipment in terms of possible side effects and generalizability, time and training demands, and costs of implementation; as well as client suitability barriers such as age, functional status, and infection control. It demonstrates that despite increasing evidence for the effectiveness of VR in post-stroke USN assessment and treatment, health care professionals are still grappling with those core issues and they are imperative to be addressed in future KT resources to support VR clinical integration outside of a research context. Similarly, the collaborative results from focus group and experts in the field on the optimal features of a VR-based USN assessment can serve to adapt current tools or to guide the development of a new tool that better suits different clients' functional capabilities and deficits (e.g., aphasic, wheelchair-bound), as well as end-users/clinicians needs (e.g., easy application/start up, print out reports, progress reports, resource/assistance, time constraint, three-dimentional immersive environment, tasks options, etc.). We suggest future presented tools to incorporate these findings which in turn could promote its adherence and satisfaction with its use in clinical settings among practicing rehabilitation professionals.

The current study also has its limitations. First, clinicians' perceptions were determined at one point in time by using a crosssectional exploratory study design. Although we consider that it is appropriate given the exploratory nature of this project, future longitudinal designs that would study these perceptions in time would be beneficial. Moreover, a true collaborative approach by including clinicians and experts in the field in the same focus groups would have been advantageous, but this was not possible given the different geographical locations and schedule conflicts. Nevertheless, individual interviews have also proven to be effective methods in gathering information and mixing qualitative methods (focus groups, interviews, surveys) as used in the present study is suggested to provide broader understanding of the phenomenon of interest that may be otherwise overlooked if a single method is used [52]. Finally, another limitation is that the evidence behind VR assessment for post-stroke USN is still limited and exploratory at the moment [19]. This implies that it may be challenging to implement practice changes in the future. Yet, the results of the present study offer preliminary steps by including the end-users/clinicians early in the process of the knowledge to action model [26], possibly facilitating forthcoming implementation of this type of system in clinical practice.

\section{Conclusion}

The present study explored the facilitators and barriers to the clinical use of VR for post-stroke USN assessment and identified features for an optimal VR-based USN assessment tool through mixed qualitative methods including focus group, self-administered questionnaires, and individual interviews. Findings show that clinicians are open to the idea of using VR for post-stoke USN assessment. Facilitators such as knowledge of the importance of USN assessment, equipment usability, client suitability, and institutional organization support can be emphasized during an implementation phase. However, therapists also identified several personal, institutional, equipment usability, and client suitability barriers that should be addressed in designing a future knowledge translation intervention prior to and during an implementation phase. The reported features of an optimal VR-based USN assessment tool by a collaborative effort of end-users and experts in the field offer invaluable concepts for the modification of alreadyexisting tools or the development of new tools. Considering those features should lead to a more effective clinical implementation of a tool while promoting its use and adherence among rehabilitation professionals.

\section{Acknowledgements}

T. O. was supported by the Richard \& Edith Strauss Fellowship in Rehabilitation Sciences and The Fonds de Recherche du Québec Santé (FRQS). This project was supported by the Canadian Institute of Health Research (MOP - 77548) and A. L. is the recipient of a Senior Scientist FRQS Salary Award. The authors would 
like to acknowledge the involvement of clinical/research coordinators, Franceen Kaizer (Jewish Rehabilitation Hospital) and Isabelle David (Institut de Réadaptation Gingras-Lindsay de Montréal), focus group study participants at both clinical sites, experts in the field for their interview time, Marco Bühler (School of Physical and Occupational Therapy, McGill University) for coding verbatim transcripts, and Myriam Villeneuve (Jewish Rehabilitation Hospital) for assistance with the focus groups.

\section{Disclosure statement}

The authors report no declarations of interest.

\section{Funding}

T. O. was supported by the Richard \& Edith Strauss Fellowship in Rehabilitation Sciences and The Fonds de Recherche du Québec Santé (FRQS). This project was supported by the Canadian Institute of Health Research (MOP - 77548) and A. L. is the recipient of a Senior Scientist FRQS Salary Award.

\section{ORCID}

Philippe S. Archambault (ID http://orcid.org/0000-0002-8656-4477

\section{References}

[1] Mayo NE, Wood-Dauphinee S, Ahmed S, et al. Disablement following stroke. Disabil Rehabil. 1999;21:258-268.

[2] Jutai JW, Bhogal SK, Foley NC, et al. Treatment of visual perceptual disorders post stroke. Top Stroke Rehabil. 2003;10:77-106.

[3] Paolucci S, Antonucci G, Grasso MG, et al. The role of unilateral spatial neglect in rehabilitation of right brain-damaged ischemic stroke patients: a matched comparison. Arch Phys Med Rehabil. 2001;82:743-749.

[4] Gillen R, Tennen H, McKee T. Unilateral spatial neglect: relation to rehabilitation outcomes in patients with right hemisphere stroke. Arch Phys Med Rehabil. 2005;86:763-767.

[5] Federation WH. Stroke 2016 [cited 2016 Oct 3]. Available from: http://www.world-heart-federation.org/cardiovascularhealth/stroke/.

[6] Buxbaum LJ, Ferraro MK, Veramonti T, et al. Hemispatial neglect: subtypes, neuroanatomy, and disability. Neurology 2004;62:749-756.

[7] Menon-Nair A, Korner-Bitensky N, Ogourtsova T. Occupational therapists' identification, assessment, and treatment of unilateral spatial neglect during stroke rehabilitation in Canada. Stroke J Cereb Circ. 2007;38: 2556-2562.

[8] Menon-Nair A, Korner-Bitensky N, Wood-Dauphinee S, et al. Assessment of unilateral spatial neglect post stroke in Canadian acute care hospitals: are we neglecting neglect?. Clin Rehabil. 2006;20:623-634.

[9] Bowen A, McKenna K, Tallis RC. Reasons for variability in the reported rate of occurrence of unilateral spatial neglect after stroke. Stroke J Cereb Circ. 1999;30:1196-1202.

[10] Berard J, Fung J, Lamontagne A. Visuomotor control post stroke can be affected by a history of visuospatial neglect. J Neurol Neurophysiol 2012;S8. doi:10.4172/2155-9562.S8001.
[11] Peskine A, Rosso C, Box N, et al. Virtual reality assessment for visuospatial neglect: Importance of a dynamic task [Letter]. J Neurol Neurosurg Psychiatry. 2011;82:1407-1409.

[12] Buxbaum LJ, Palermo MA, Mastrogiovanni D, et al. Assessment of spatial attention and neglect with a virtual wheelchair navigation task. J Clin Exp Neuropsychol. 2008;30:650-660.

[13] Aravind G, Lamontagne A. Perceptual and locomotor factors affect obstacle avoidance in persons with visuospatial neglect. J Neuroeng Rehabil. 2014;11:38.

[14] Dvorkin AY, Bogey RA, Harvey RL, et al. Mapping the neglected space: gradients of detection revealed by virtual reality. Neurorehabil Neural Repair. 2012;26:120-131.

[15] Sheridan TB. Musings on telepresence and virtual presence. Presence Teleop Virtual Environ. 1992;1:120-126.

[16] Weiss $P$, Jessel AS. Virtual reality applications to work. Work. 1998;11:277-293.

[17] Rizzo A, Kim GJ. A SWOT analysis of the field of VR rehabilitation and therapy. Presence Teleop Virtual Environ. 2005;14:119-146.

[18] Mantovani A, Castelnuovo G. Sense of presence in virtual training: enhancing skills aquisition and transfer of knowledge through learning experience in virtual environments. In: Riva G, Davide, F., Ijsselsteijn, W.A., editors. Being there: concepts, effects and measurement of user presence in synthetic environments. Amsterdam, The Netherlands: IOS Press; 2003.

[19] Ogourtsova T, Souza Silva W, Archambault PS, et al. Virtual reality treatment and assessments for post-stroke unilateral spatial neglect: a systematic literature review. Neuropsychol Rehabil. 2017;27:409-454.

[20] Broeren J, Samuelsson H, Stibrant-Sunnerhagen K, et al. Neglect assessment as an application of virtual reality. Acta Neurol Scand. 2007;116:157-163.

[21] Buxbaum LJ, Dawson AM, Linsley D. Reliability and validity of the virtual reality lateralized attention test in assessing hemispatial neglect in right-hemisphere stroke. Neuropsychology 2012;26:430-441.

[22] Kim J, Kim K, Kim DY, et al. Virtual environment training system for rehabilitation of stroke patients with unilateral neglect: crossing the virtual street [Research Support, Non-U.S. Gov't]. Cyberpsychol Behav. 2007;10:7-15.

[23] Tanaka $T$, Ifukube $T$, Sugihara $S$, et al. A case study of new assessment and training of unilateral spatial neglect in stroke patients: effect of visual image transformation and visual stimulation by using a head mounted display system (HMD). J Neuroeng Rehabil. 2010;16:20.

[24] Tanaka T, Sugihara S, Nara H, et al. A preliminary study of clinical assessment of left unilateral spatial neglect using a head mounted display system (HMD) in rehabilitation engineering technology. J Neuroeng Rehabil. 2005;2:31.

[25] Vishwanath A, Scamurra SD. Barriers to the adoption of electronic health records: using concept mapping to develop a comprehensive empirical model. Health Informatics J. 2007;13:119-134.

[26] Graham ID, Logan J, Harrison MB, et al. Lost in knowledge translation: time for a map? J Contin Educ Health Prof 2006;26:13-24.

[27] Levac D, Glegg SM, Sveistrup $H$, et al. A knowledge translation intervention to enhance clinical application of a virtual reality system in stroke rehabilitation. BMC Health Serv Res. 2016;16:557. 
[28] Glegg SMN, Holsti L, Stanton S, et al. Evaluating change in virtual reality adoption for brain injury rehabilitation following knowledge translation. Disabil Rehabil Assist Technol. 2017;12:217-226.

[29] Levac DE, Miller PA. Integrating virtual reality video games into practice: clinicians' experiences. Physiother Theory Pract. 2013;29:504-512.

[30] Kramer TL, Pyne JM, Kimbrell TA, et al. Clinician perceptions of virtual reality to assess and treat returning veterans. Psychiatr Serv. 2010;61:1153-1156.

[31] Markus LA, Willems KE, Maruna CC, et al. Virtual reality: feasibility of implementation in a regional burn center. Burns. 2009;35:967-969.

[32] Ogourtsova TAS, Sangani S, Lamontagne A, editors. Goaldirected navigation and detection in post-stroke unilateral spatial neglect: the impact of virtual reality scene complexity. Poster session presented at Canadian Stroke Congress 2016 Sept 14-17; Quebec City, Canada.

[33] Patton MQ. Enhancing the quality and credibility of qualitative analysis. Health Serv Res. 1999;34:1189-1208.

[34] Sandelowski M. Whatever happened to qualitative description?. Res Nurs Health. 2000;23:334-340.

[35] Morgan DL, Krueger RA. The focus group kit. London (UK): Sage; 1997.

[36] Thorne SE. Interpretive description (Developing qualitative inquiry). Walnut Creek (CA): Left Coast Press; 2008.

[37] Carlsen B, Glenton C. What about N? A methodological study of sample-size reporting in focus group studies. BMC Med Res Methodol. 2011;11:26.

[38] Krueger RA, Casey MA. Focus groups: a practical guide for applied research. 4th ed. Los Angeles: SAGE; 2009.

[39] Kitzinger J. Qualitative research. Introducing focus groups. BMJ. 1995;311:299-302.

[40] Bender DE, Ewbank D. The focus group as a tool for health research: issues in design and analysis. Health Transit Rev. 1994;4:63-80.
[41] Fern EF. The use of focus groups for idea generation: the effects of group size, acquaintanceship, and moderator on response quantity and quality. J Market Res. 1982;19:1-13.

[42] Fusch PIN, Ness LR. Are we there yet? Data saturation in qualitative research. Qual Rep. 2015;20:1408-1416.

[43] Venkatesh VMM, Davis G, Davis F. User acceptance of information technology: toward a unified view. Mis Quart. 2003;27:425-478.

[44] Thomas TD, Singh L, Gaffar K. The utility of the UTAUT model in explaining mobile learning adoption in higher education in Guyana. Int J Educ Dev Using ICT. 2013;9:71-85.

[45] Liu L, Miguel Cruz A, Rios Rincon A, et al. What factors determine therapists' acceptance of new technologies for rehabilitation - a study using the unified theory of acceptance and use of technology (UTAUT). Disabil Rehabil. 2015;37:447-455.

[46] Denzin NK. Sociological methods: a sourcebook. 2nd ed. New York (NY): McGraw-Hill; 1978.

[47] Hsieh HF, Shannon SE. Three approaches to qualitative content analysis. Qual Health Res. 2005;15:1277-1288.

[48] Wilson BA, Evans JJ, Emslie $\mathrm{H}$, et al. The development of an ecologically valid test for assessing patients with a dysexecutive syndrome. Neuropsychol Rehabil. 1998;8:213-228.

[49] Heselmans A, Aertgeerts B, Donceel P, et al. Family physicians' perceptions and use of electronic clinical decision support during the first year of implementation. J Med Syst. 2012;36:3677-3684.

[50] Hanson CWJ, Neiger B, Thackeray R, et al. Use and acceptance of social media among health educators. Am J Health Educ. 2011;42:197-204.

[51] Holtz BKS. Understanding nurse perceptions of a newly implemented electronic medical record system. J Technol Hum Serv. 2011;29:247-262.

[52] Morse JM. Mixing qualitative methods. Qual Health Res. 2009;19:1523-1524. 